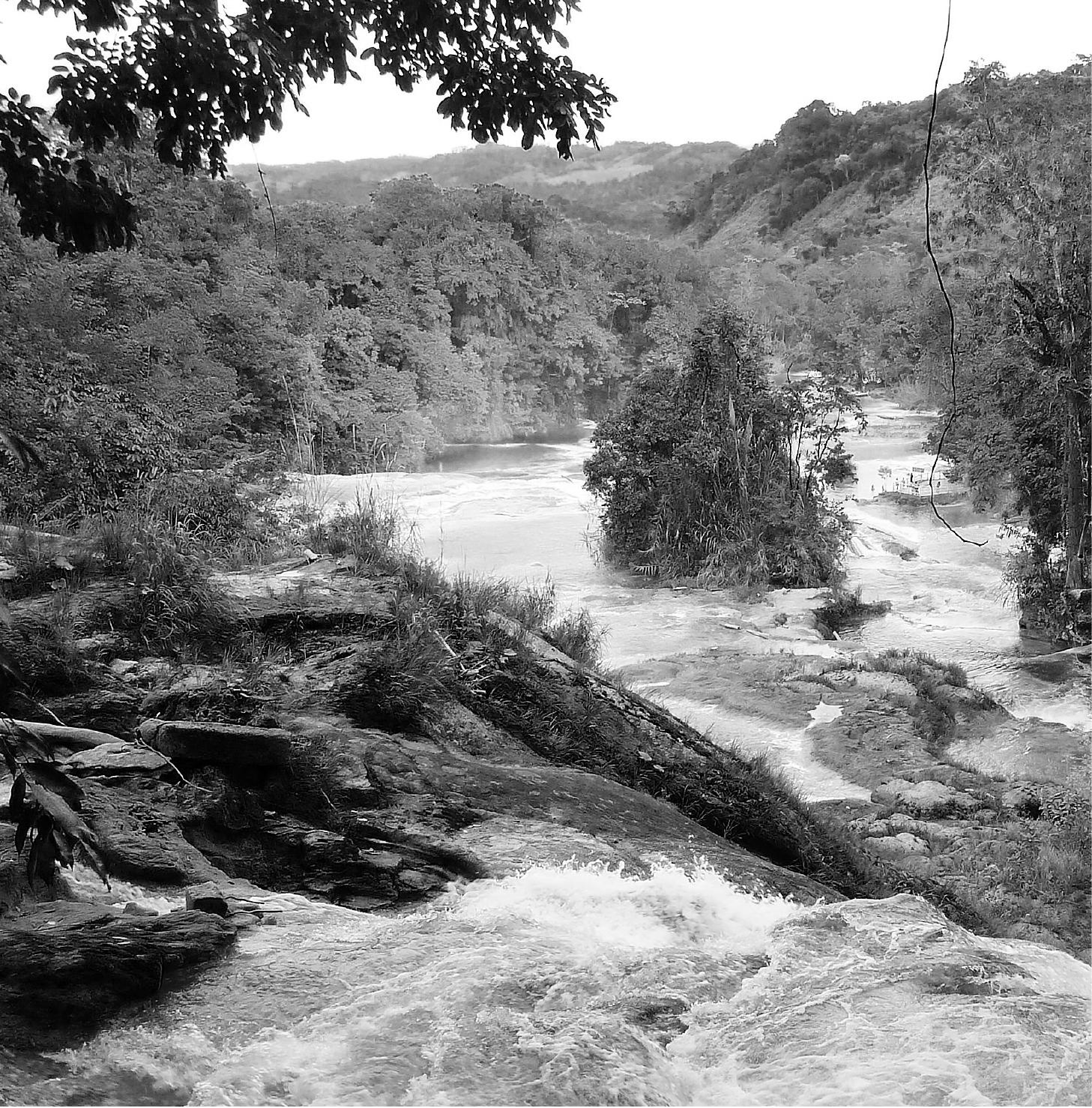

AIBR

Revista de Antropología

Iberoamericana

www.aibr.org

Volumen 16

Número 1

Enero - Abril 2021

Pp. $61-87$

Madrid: Antropólogos

Iberoamericanos en Red.

ISSN: 1695-9752

E-ISSN: 1578-9705

\section{Los lenguajes del pensamiento}

\section{Lydia Rodríguez Cuevas}

Departamento de Antropología. State University of New York at Potsdam

Recibido: 13.08.2019

Aceptado: 03.07.2020

Dol: 10.11156/aibr.160104 


\title{
RESUMEN
}

La relatividad lingüística implica que la presencia o ausencia de distintas categorías gramaticales, así como distintos estilos discursivos, pueden influir en cómo percibimos y experimentamos el mundo que nos rodea. Los mayas choles de Chiapas hablan una lengua que no tiene tiempos verbales, y que utiliza el aspecto gramatical para expresar nociones temporales. Este artículo explora el efecto que la ausencia de tiempos verbales puede tener en la percepción de imágenes secuenciales. En este estudio se presentaron una serie de estímulos visuales a varios hablantes monolingües choles, que consistían en distintos tipos de imágenes secuenciales que los hablantes tenían que describir. Se les mostraron una historia larga a través de múltiples secuencias de imágenes, y varias historias breves compuestas por un mínimo de dos y un máximo de cinco imágenes secuenciales. Ninguna de las narraciones que los choles hicieron de la historia larga o de las historias cortas poseían una lógica secuencial cronológica, y todas las imágenes secuenciales fueron descritas en términos no secuenciales por los hablantes choles. En línea con la hipótesis de relatividad lingüística, en el artículo se plantea que este curioso efecto discursivo puede estar causado por la ausencia de tiempos verbales en la lengua chol.

\section{PALABRAS CLAVE}

Relatividad lingüística, secuencialidad, Mesoamérica, mayas choles.

\section{THE LANGUAGES OF THE MIND}

\begin{abstract}
Linguistic relativity, rightly understood, implies that the presence or absence of certain grammatical categories and discursive styles can influence how we perceive and experience the world around us. In this study, monolingual speakers of Chol Mayan, a tenseless language, were shown a series of visual stimuli portraying different sequences of events, and were asked to describe what they saw to an interviewer. Participants were shown a long silent story composed of many sequential images, and a set of shorter stories composed of a minimum of two sequential images and a maximum of five sequential images. None of the stories that the Chol speakers told in response to the stimulus followed a sequential-chronological order, and all sequential images were described in non-sequential terms. In line with the linguistic relativity hypothesis, it is argued that this interesting discursive effect may be the result of the tenselessness of the Chol language.
\end{abstract}

\section{KEY WORDS}

Linguistic relativity, sequentiality, Mesoamerica, Chol Mayan. 


\section{Agradecimientos}

Deseo agradecer a Eve Danziger, quien me introdujo a la relatividad lingüística, y cuya influencia en este artículo y en mi trayectoria intelectual es inestimable. Sergio D. López realizó las viñetas del test de secuencialidad, y me apoyó incondicionalmente durante todo el trabajo de campo. Agradezco sinceramente a todos los hablantes choles que participaron en las tareas cognitivas con gran paciencia y empatía. Finalmente, esta investigación no hubiera sido posible sin el generoso apoyo de la Wenner-Gren Foundation.

Cualquier estudiante que ha tomado un curso introductorio sobre la historia de la antropología ha oído hablar de la llamada «hipótesis de relatividad lingüística", formulada por Benjamin Lee Whorf (Whorf, 1941; Whorf, 1956). Esta hipótesis se basa en la idea de que la lengua que hablamos ejerce una profunda influencia en cómo categorizamos y experimentamos la realidad, en lo que los antropólogos llamamos «cosmovisión». La hipótesis es provocativa porque implica que distintas lenguas se traducen en distintas cosmovisiones. Pero como su nombre indica, es una hipótesis, una idea que, a fecha de hoy, continúa sin ser plenamente refutada o corroborada ${ }^{1}$.

Lo cierto es que, tanto si estamos de acuerdo con esta idea como si no, la hipótesis de relatividad lingüística ha sido uno de los conceptos más prolíficos de la historia de la antropología, y, décadas después de haber sido formulada, continúa estimulando la producción de estudios que intentan probar o refutar esta provocativa idea. La hipótesis ha cobrado una vida propia que, afortunadamente, no está confinada estrictamente al ámbito académico. Cada cierto tiempo sale un artículo en el New York Times o en otras fuentes de difusión popular resumiendo los últimos estudios que se han hecho sobre cómo hablantes de una u otra lengua perciben algún aspecto de la realidad de forma distinta. Y cada cierto tiempo académicos de gran renombre descienden de la torre de marfil para escribir monográficos dirigidos a un público general, intentando desmontar esta misma idea (McWhorter, 2014; Pinker, 2007). Incluso aparecen películas de ciencia ficción inspiradas por la hipótesis, como Arrival (La llegada), de Dennis Villeneuve (2016).

1. Sobre los orígenes y diversas influencias que tuvieron en Whorf autores como Humboldt, Sapir y Boas, entre otros, véase Lucy (1992a y b, y 1997), y Gumperz y Levinson (1996). Lee (1996) ofrece también una excelente recapitulación de la hipótesis y las posturas críticas que ha suscitado la hipótesis. Gentner y Goldin-Meadow (2003) han realizado una recopilación de estudios experimentales más recientes, que se posicionan en los dos lados del debate, a favor y en contra de la relatividad lingüística. 
¿Por qué suscita esta idea tanto rechazo en algunos y tanta pasión en otros? Los argumentos de sus detractores recuerdan vagamente a los de aquellos que equiparan el relativismo cultural con el relativismo moral. Si distintas lenguas se traducen en diferentes formas de ver, experimentar, y categorizar la realidad, los seres humanos están condenados a no poder entender más allá de aquello que las categorías gramaticales de sus lenguas nativas les fuerzan a experimentar. Para los detractores de la hipótesis, a quienes podemos llamar «babelistas», si tomáramos en serio lo que plantea la hipótesis, tendríamos que admitir que las distintas lenguas son elementos distanciadores, algo que separa a los seres humanos en vez de unirlos. Los detractores consideran que la relatividad lingüística es incompatible con el universalismo cultural. Por otra parte, para los defensores de la hipótesis, las lenguas son elementos flexibles y socialmente moldeables que responden a las necesidades diversas de cada cultura. La relatividad lingüística, bien entendida, no implica que la lengua nos «fuerce» a ver el mundo de determinada manera, sino más bien lo opuesto: aprender una lengua distinta es la clave para experimentar una realidad distinta, o para mirar al mundo desde otra perspectiva. El ser humano es diverso por naturaleza y esto no son malas noticias; al contrario, es algo que celebrar.

Años después de haber leído a Whorf por primera vez, continúo haciéndome las mismas preguntas que siguen sin ser resueltas en el debate entre «babelistas» $\mathrm{y}$ «relativistas»: ¿Es el conocimiento de distintas lenguas la clave para la interpretación de las culturas en las que están inmersas? ¿Puede un antropólogo estudiando una cultura ajena penetrar en un sustrato de la realidad más profundo de esa cultura si aprende la lengua? La investigación antropológica rara vez utiliza la autorreflexividad para analizar el impacto que hablar una lengua de campo puede tener en la calidad de la información recogida por el profesional de la antropología (Tanu y Dales, 2016). Es precisamente este necesario ejercicio de autorreflexividad lo que que en última instancia ha suscitado las reflexiones plasmadas en este artículo.

\section{Whorf Ilega a Chiapas}

Cualquiera que esté intrigado por saber si la lengua es la clave para la interpretación de la cultura, debe comenzar por aprender una lengua distinta a su lengua nativa. Y cuanto más distinta, mejor, pues más extrañamiento antropológico producirá. Así comenzó mi viaje al aprendizaje del chol, una lengua maya occidental que se habla mayoritariamente en el mexicano Estado de Chiapas, y en la frontera con Guatemala. Los choles son, al igual que muchos otros grupos mayas, agricultores de roza y que- 
ma, siendo el cultivo de maíz, frijol, y diversos tipos de calabaza su principal actividad de subsistencia. Algunos choles también compatibilizan sus milpas (campos de maíz) con el cultivo de café, que aporta algo de dinero en efectivo a la economía familiar. A pesar de no haber sido el foco de atención en el famosísimo Harvard Chiapas Project, quizá eclipsados por los vecinos tzotziles y tzeltales, los choles han sido objeto de más recientes estudios etnográficos (Alejos García, 1999; Imberton-Deneke, 2002 y 2016; López Martínez, 2013; Pérez Chacón, 1988).

Si bien la tensión intelectual que se produce al aprender una lengua tan distinta a la propia es profundamente productiva, el coste de este proceso es muy elevado. El antropólogo en ciernes tiene que invertir meses, a veces años, en estudiar la lengua para ser capaz de mantener una conversación fluida con los hablantes nativos. Mi proceso de aprendizaje de la lengua chol no fue ninguna excepción en este sentido. Cuando, después de lo que parecía una eternidad estudiando chol, empecé a ser capaz de hablarlo con cierta fluidez, comencé a pedir a mis amigos choles que me contaran historias tradicionales: qué mejor forma de conseguir textos para analizar y a la vez aprender elementos claves del folclore y la mitología chol.

Lo primero de lo que me di cuenta es que las historias que contaban los hablantes monolingües choles eran bastante distintas a las historias que contaban los hablantes bilingües de chol y español, o los hablantes monolingües de español. Resultaban imposibles de entender si uno se empeñaba en construir una línea argumental cronológica, donde eventos anteriores preceden a eventos posteriores. En las historias choles, los personajes se mueven con total libertad entre escenas, que son como episodios autocontenidos o independientes, sin seguir un orden cronológico (Rodríguez, 2016). La historia puede empezar in medias res, y de ahí puede ir hacia adelante o hacia atrás, o desarrollarse como en un zigzag, volviendo sobre escenas ya mencionadas, o transportándonos de golpe a escenas que parecen no estar conectadas con lo anterior. Después de tantos meses aprendiendo las sutilezas de un sistema lingüístico tan distinto al de mi lengua nativa comencé a preguntarme en qué consistían esas fascinantes historias que no resultaba posible entender en términos cronológicos. ¿Sería que la lógica secuencial narrativa no era importante en la tradición oral chol?

Los largos meses dedicados al estudio minucioso de la gramática chol empezaron a aportar alguna luz en el rompecabezas de las historias tradicionales que poseían una estructura narrativa tan diferente. En una lengua como el español, cada verbo tiene que ir obligatoriamente conjugado con tiempos verbales. Pero el chol, al igual que la mayor parte de las otras len- 
guas mayas, carece de tiempos verbales que han de ser marcados obligatoriamente en el verbo. Por ejemplo, la frase mi kmajlel tyi cholel se puede traducir en español por «yo voy a la milpa», "yo iba a la milpa», o «yo iré a la milpa». La única manera de saber si la acción de ir a la milpa se ubica en el pasado, presente, o futuro es por contexto. En chol, no obstante, este verbo está marcado con la categoría gramatical de aspecto, que describe cualitativamente la acción verbal. El aspecto nos dice, por ejemplo, si una acción es habitual o puntual, o si está acabada o inacabada. El predicado mi kmajlel tyi cholel quiere decir que la acción de ir a la milpa es habitual y no puntual, y que de ninguna manera está completa o finalizada. Pero no podemos saber si desde la perspectiva del hablante esa acción es habitual en el presente, si lo era en el pasado, o si lo será en el futuro.

Esto no quiere decir que los choles no puedan, si así lo desean, expresar si una acción ocurre en el pasado, el presente, o el futuro. En lenguas que carecen de tiempos verbales existen múltiples estrategias para expresar estos conceptos, entre ellas, el uso de adverbios temporales (Klein, 2009; Tonhauser, 2015). En chol, al igual que en muchas otras lenguas sin tiempos verbales, se pueden utilizar adverbios temporales para expresar si una acción ocurre antes, simultáneamente, o después del momento del habla, que es lo que se expresa mediante los tiempos verbales (Vázquez Álvarez, 2011; Rodríguez, 2016 y 2019). No obstante, la diferencia clave entre lenguas como el español y el chol es la obligatoriedad de estas categorías. Los verbos en español tienen que ir conjugados con tiempos verbales. En chol, aunque se pueda expresar mediante determinados adverbios si una acción ocurre antes, durante, o después del momento del habla, esto es completamente opcional (Rodríguez, 2016 y 2019). La gramática española, en términos de Whorf, «invita» a pensar los verbos como si estuvieran inevitablemente ligados a los tiempos verbales. La gramática chol no lo hace. He ahí la clave de la ausencia de una lógica lineal en las historias choles: si cada frase de la que se compone una historia no tiene que poseer un verbo conjugado con tiempos verbales, es difícil anclarla a un momento concreto ubicado en una línea temporal imaginaria compuesta por una secuencia de acontecimientos pasados, presentes, y futuros.

\section{«Pensar para hablar» en chol}

Si la lengua chol no fuerza a sus hablantes a usar tiempos verbales para describir secuencias de acontecimientos, ¿hasta qué punto está ausente esta lógica secuencial de las historias choles? Puesto que las historias tradicionales choles que yo había recopilado no empleaban ninguna lógica secuencial, una forma de responder a esta pregunta era mostrar a los 
hablantes choles imágenes secuenciales, y pedirles que contaran la «historia» que se les había mostrado.

En los años ochenta, Dan Slobin y Ruth Berman desarrollaron un famoso estudio comparativo translingüístico donde enseñaron a hablantes de cuatro lenguas distintas ${ }^{2}$ una historia en imágenes, sin ningún tipo de palabras escritas, y se les pidió que describieran esa historia (Slobin, 1987 y 1996). En este estudio, Slobin y sus colegas demostraron que, utilizando el mismo estímulo, las historias que los hablantes contaban eran distintas —no únicamente la forma, sino también el contenido variaba- y las variaciones que se apreciaban estaban ligadas a la presencia o ausencia de determinadas categorías gramaticales en cada una de estas lenguas. Por ejemplo, el hecho de que las lenguas tuvieran o no determinados tiempos verbales, o diversos tipos de aspecto gramatical, influenciaba el estilo retórico de las narraciones, la descripción de determinadas imágenes y la interpretación de las acciones que desarrollaban los personajes.

Inspirada por el trabajo de Slobin, mostré el mismo libro que ellos usaron en ese estudio — Rana, ¿̇ónde estás? (Mayer, 1969)— a cuatro hablantes monolingües choles. Las 24 imágenes en este libro de ilustraciones muestran la historia de un niño que captura una rana y la mete en un frasco de cristal. Mientras el niño duerme, la rana se escapa y el niño se dispone a buscarla, acompañado de su mascota, un perro. El niño primero busca a la rana en el bosque, donde encuentra un tronco, y cuando va a mirar dentro del tronco se encuentra una colmena de abejas. Las abejas, molestas por la incursión, persiguen al niño y a su mascota, que salen huyendo. Los protagonistas continúan buscando a la rana, y en las siguientes imágenes se muestra a un ciervo, que toma al niño en sus cuernos, y le arroja a un pequeño estanque, donde finalmente el niño encuentra a la rana.

Puesto que la gran mayoría de choles que pertenecen a la generación adulta actual son bilingües en chol y español, la mayor parte de hablantes monolingües suelen ser de edad más avanzada. Los cuatro hablantes entrevistados tenían edades comprendidas entre los 55 y los 75 años. Ninguno había recibido escolarización formal, y los cuatro se empleaban en ocupaciones tradicionales, siendo las principales actividades de subsistencia el trabajo en la milpa y el cafetal. Dos de ellos eran varones y dos eran mujeres. Los hablantes choles examinaron cuidadosamente el libro página a página, imagen por imagen. Las descripciones que dieron eran muy similares entre sí, y se caracterizaban por un estilo retórico muy particular, cuya principal característica era la ausencia de secuencialidad. Los

2. El estudio originario se hizo con cuatro lenguas: español, inglés, alemán, y hebreo; posteriormente se ha repetido con muchas otras lenguas, entre ellas el finlandés, islandés, japonés, mandarín, ruso, y turco. 
choles mencionaban eventos aislados que ellos recordaban, pero no hacían conexiones entre esos eventos. Los elementos que más se repetían en las descripciones choles eran los sustantivos «niño» (aläl/bityal), "persona» (kixtyaño), "perro» (tsi') y "ciervo» (chijmay/me'/kolembä ixulu "el de los cuernos grandes»). La mayor parte de las descripciones utilizaban sustantivos, precedidos por la frase tyi jk'ele... ("vi...») o ya'añ... ("ahí hay...»). Esta fue la historia más completa de todas las que obtuve, narrada por un hablante monolingüe chol llamado Don Fernando: «Estas cosas vi, como un niño con su perro, o este... había muchas cosas...como... como este... ciervo de los cuernos grandes, porque se va cargando al niño, o dónde lo tira... Porque aquel, creo que es brujo también, o quizás no. [Vi] dónde le tiró. Vi muchas cosas ahí. Pero eran de otro mundo".

De todas las imágenes que componen la historia, la que más memorable le resulta es aquella que contiene "este ciervo, el de los cuernos grandes...» que puede o no ser un brujo. Sin lugar a dudas, Don Fernando está relacionando el ciervo de los cuernos grandes con un personaje del folclore chol, el Tientzun, una criatura terrorífica que es un chivo gigantesco de grandes cuernos, a quien los choles a veces relacionan con los «trabajos» de brujería.

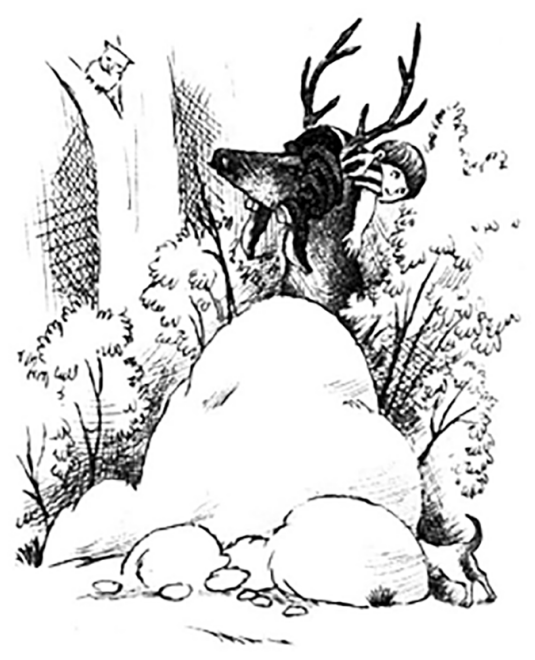

Figura 1. «El de los cuernos grandes». Fuente: Frog, Where Are You? p. 18. Ilustración de Mercer Mayer.

A pesar de que resulta evidente que esta «historia» no está relatada en términos secuenciales, merece la pena examinar la frase donde el ciervo arroja al niño (al estanque). En esta escena, que en el libro original está 
plasmada en tres imágenes, se muestra primero al ciervo llevando al niño en sus cuernos (Figura 1), y en las siguientes imágenes se muestran al niño y al perro, primero a mitad de la caída, y luego se les ve dentro del agua (Figura 2). La implicación aquí es que llevar al niño entre los cuernos y tirarlo al agua forma una secuencia de acontecimientos. ¿Pero es esa la interpretación chol de estas imágenes?

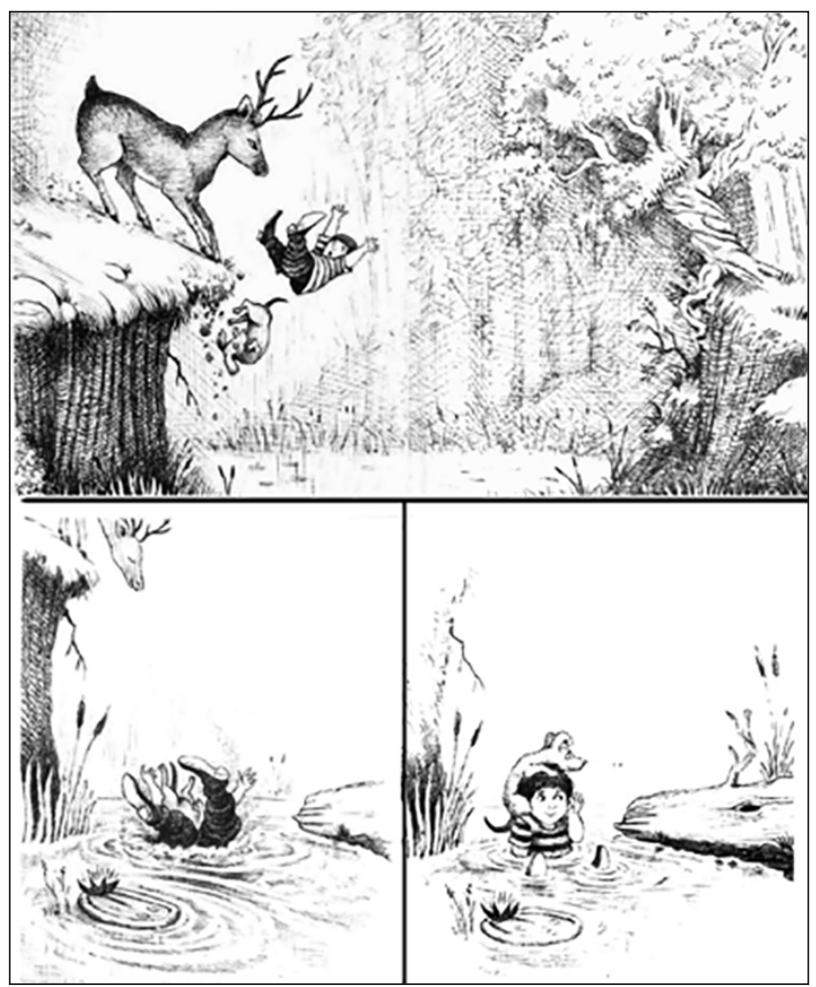

Figura 2. "O dónde lo tira». Fuente: Frog, Where Are You? Imagen superior: pp. 20-21. Imagen inferior: pp. 22-23. Ilustraciones de Mercer Mayer.

Prestemos atención a qué es exactamente lo que dice Don Fernando:

(1) Jiñtyak tyi jk'ele ta'che' bajche' aläl, Estas cosas vi, como un niño

(2) yik'oty jiñi ts'ï, o este añ kabältyak, con su perro, o este... había muchas cosas... 
(3) che' bajche' jiñi me' kolembä ixulu, como... como este... ciervo de los cuernos grandes

(4) ejke choñkol ikech majlel jiñi aläl, porque se va cargando al niño

(5) o baki mi ichok o... o dónde lo tira...

(6) jiñba tyi ikaj bajche' li xi’baj mi kñatyañ jéel... porque aquel, creo que es brujo también...

Aunque parezca haber una secuencia implicada entre «se va cargando el niño» y "o dónde lo tira», en chol esto no es necesariamente así. El segundo predicado "o dónde lo tira» (línea 5) en realidad es un complemento del verbo principal en línea (1) «estas cosas vi...». Estrictamente hablando, aunque estemos tentados a pensar que hay una conexión secuencial entre los dos predicados verbales, "cargando al niño» y «lo tira», la gramática chol no implica tal secuencialidad. Cargar al niño y tirarlo al río no son las dos partes de una secuencia, sino dos de las «cosas» (jiñtyak) que Don Fernando vio en el libro. Es importante también resaltar que la segunda oración «o dónde lo tira» está introducida por una conjunción disyuntiva, «O», un préstamo del español. El significado para Don Fernando es «vi esto, lo otro, o lo otro», no «vi esto, después lo otro». Lo que vio, además de un ciervo cargando al niño en sus cuernos, es dónde lo arrojó, no que primero lo llevaba en sus cuernos, y luego lo arrojó. Esa es una interpretación a la que invitan nuestras categorías gramaticales, pero no las del chol.

\section{Inversiones de figura y fondo}

Si las historias tradicionales choles no poseen una lógica de ordenamiento cronológico-secuencial, y si una historia claramente secuencial como la de Rana, ¿dónde estás? no es interpretada secuencialmente por los hablantes monolingües de chol, cabe preguntarse cómo se construye la propia idea de secuencialidad en la lengua, la cultura, y el pensamiento chol. El siguiente paso sería, por tanto, averiguar si los hablantes choles pueden realizar una implicatura de secuencialidad ${ }^{3}$ entre dos o más imágenes, o

3. El término «implicatura de secuencialidad» se refiere a una implicación pragmática (Grice, 1975) donde lo que se implica —el «implicatum» en términos griceanos- es un ordenamiento cronológico-secuencial entre dos o más oraciones, cláusulas verbales, o, en este caso, imágenes. 
si la secuencialidad es un elemento «opcional», al igual que lo es el uso de elementos discursivos para indicar si un evento es anterior, simultáneo, o posterior al momento del habla.

En el caso de la historia de Rana, ¿dónde estás?, con sano escepticismo podríamos decir que la ausencia de secuencialidad en las narrativas choles se debe a que el contenido de la historia era demasiado ajeno a la lógica cultural chol, o a que la historia era demasiado larga. Por lo tanto, para indagar en la idea de secuencialidad hemos de recurrir a historias que, en primer lugar, no resulten extrañas desde la perspectiva cultural chol, y, en segundo lugar, que no sean tan largas como la de Rana, ¿dónde estás? Lo ideal es utilizar una historia en miniatura, o lo que Labov ha denominado "narrativa mínima» (Labov, 1972). Una narrativa mínima es «una secuencia de dos cláusulas [verbales] que están ordenadas temporalmente: es decir, alterar el orden [de estas dos cláusulas] resultaría en una alteración de la secuencia temporal de la interpretación semántica original... una narrativa mínima se define por contener una única conexión temporal [entre dos cláusulas]»(Labov, 1972: 360-361).
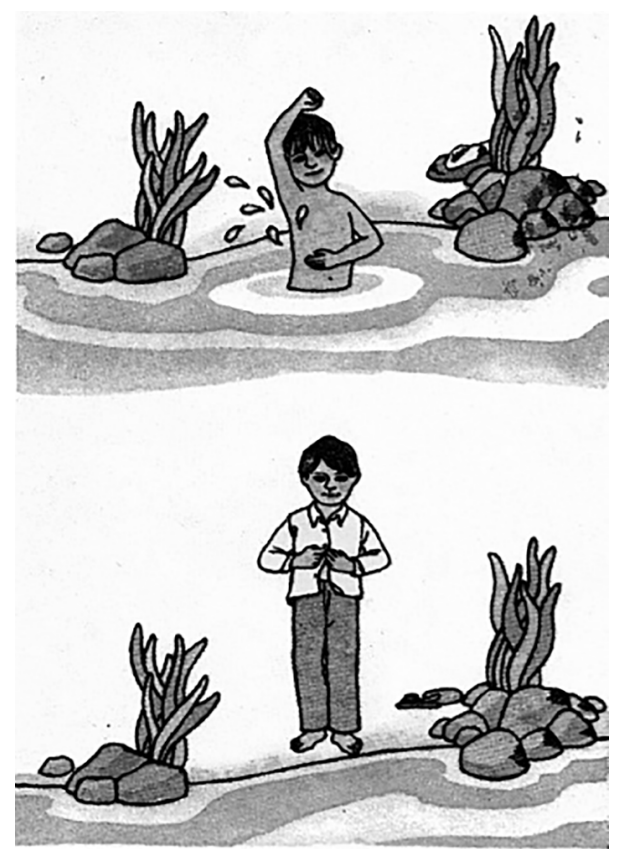

Figura 3. Secuencia de dos imágenes. Fuente: Mi Primer Libro (Secretaría de Educación Pública, 1981: 33). Ilustración realizada por Irene García. 
En la imagen que se muestra en la Figura 3 existe una implicatura de narrativa mínima entre la parte de arriba y la parte de abajo: primero, un niño se está bañando en el río; después, el niño se está vistiendo. El contenido de la imagen es algo que culturalmente no sorprende en el ámbito chol, pues los choles habitualmente se bañan en ríos. Esta es la historia que un hablante de inglés norteamericano contó después de mostrársele la imagen:

\begin{abstract}
Hay un niño en un estanque, y se está bañando, su ropa está a un lado, y se está lavando, frotándose aquí [realiza un gesto icónico que muestra la forma en la que el niño de la imagen se está frotando con la esponja], tiene el brazo subido, entonces... está... lavándose, y luego en la siguiente imagen está completamente vestido, o se está vistiendo, abrochándose la camisa, tiene puestos los pantalones de nuevo, y está en frente del estanque.
\end{abstract}

Esta es una narrativa bastante estándar para hablantes de lenguas como el inglés o el español; ambas son lenguas de la familia indoeuropea que comparten un elevado número de rasgos gramaticales, entre ellos la inflexión obligatoria de los verbos con tiempos verbales. El narrador puede dar mayor o menor detalle en su historia, puede usar una narrativa mínima o varias, pero en todos los casos se asume que el protagonista de la historia es un niño (el niño de la imagen superior y la inferior son el mismo), no dos niños distintos, y también que existe una secuencia temporal entre al menos dos acciones del niño: bañarse y vestirse, siendo la primera cronológicamente anterior a la segunda. No se puede decir lo mismo de los hablantes monolingües choles a quienes mostré la misma imagen. Ni una sola de las nueve personas a las que mostré la imagen ${ }^{4}$ dio una narración secuencial remotamente parecida a la anterior. Para los choles, en la imagen aparece o bien una persona ejecutando una acción (no una secuencia de dos acciones), o dos personas haciendo dos acciones independientes.

Entre los hablantes choles que solo identificaron a una persona en la imagen, uno de ellos simplemente la describe con una forma genérica para denominar personas del género masculino en chol ombrejixtyo ta' yila, "parece que es un hombre». A otro hablante, el elemento que más le llamó la atención fue la ropa del niño: su primera frase es boñ ipislel «[están/hay] sus ropas dibujadas». Luego, apunta directamente al niño

4. Estos nueve hablantes tenían edades comprendidas entre los 24 y los 85 años. Dos eran varones y el resto eran mujeres, pues el monolingüismo es más común en mujeres que en hombres en el área chol. Estos hablantes no habían sido escolarizados o habían tenido muy poca exposición a la lectoescritura, y se dedicaban al trabajo en el campo en el caso de los varones y al trabajo doméstico en el caso de las mujeres. 
en la parte superior de la imagen y dice jiñi tsämel muk, "este se está bañando». Es claro que no existe una conexión secuencial o una narrativa mínima entre "[están/hay] sus ropas dibujadas» y "este se está bañando", partiendo del hecho de que la primera cláusula ni siquiera es un predicado verbal, pues en chol, como en muchas otras lenguas, se pueden crear oraciones atributivas ${ }^{5}$ en ausencia de verbo copulativo (en este caso, el verbo "haber» o "estar»), simplemente mediante la yuxtaposición de un sustantivo y un adjetivo. Lo que el hablante chol dice, literalmente, es «dibujadas ropas» (se entiende, sobre el soporte de papel que se le está mostrando).

En otro de los casos, la hablante es ambigua con respecto a si en la imagen hay dos niños, o si es el mismo niño. Pero en su descripción tampoco incluye ninguna conexión secuencial entre las dos imágenes. Lo que primero menciona no es al niño, sino elementos del paisaje: chébä tyuñ, chuxka yes ibaj ili, yopotye?? "Esto es una piedra. ¿Qué es esto?, ¿hojas?» Tras nombrar la piedra y las hojas, su atención se dirige hacia el niño que se está bañando: kixtyaño ibaj ili, ts'ämel ta' muk ili ibajñel «Este es una persona, se está bañando solo». Seguidamente continúa nombrando otros elementos en la imagen, mientras los señala con el dedo: Ja' yila ibaj ili. Tyuñ iliyi. Machäch lu'ili? Lu' jiñ ta'i, «Esto parece agua. Esto de aquí es una piedra. ¿No es eso todo? Eso es todo». Y justo antes de finalizar su descripción, se da cuenta del niño en la segunda imagen y dice choñkox ixojo ipisleli "Se están cambiando sus ropas». Es interesante el uso del plural en esta frase, pues, aunque solo uno de los dos niños en la imagen aparece cambiándose la ropa, de nuevo la elección del plural probablemente indica que ve dos niños, y no dos acciones secuenciales realizadas por el mismo niño. En cualquier caso, incluso si se estuviera refiriendo a un único niño, resulta claro que no se establece ningún tipo de narrativa mínima o conexión secuencial entre las acciones del niño de la primera imagen y las del niño de la segunda.

El resto de los hablantes describen la imagen haciendo referencia a dos individuos separados, no conectados el uno con el otro, y usan específicamente marcadores de plural para referirse a los dos niños. Una de las hablantes inicia su descripción así: kixtyañotyak la'saj añtyaki «Estos son personas pequeñitas», una forma afectiva de referirse a los niños. Luego, describe lo que cada una de las dos personas está haciendo: choñkoläch ijam ibujk, yik'oty choñkol its'ämel, «Este está abriendo

5. Oraciones atributivas son oraciones simples formadas por un sujeto, un verbo copulativo (como ser, parecer, o estar), y un argumento atributo, que expresa alguna cualidad del sujeto: por ejemplo, «la ropa es hermosa», o «el niño parece cansado». 
su camisa, junto con este que se está bañando». Otra hablante llama a los dos niños X-tyämijolob «los del pelo largo». El Tyämijol es un personaje sobrenatural del folclore chol que vive en una cueva y rapta a mujeres por la noche (Vázquez Álvarez, 2011). En cualquier caso, para esta mujer en la imagen no hay uno, sino dos Tyämijolob, lo que se indica en chol mediante el sufijo plural -ob. En otro caso, una de las hablantes interpretó que los niños eran de dos géneros distintos, llamándolos alo' "muchacho" y Yäñ. X-k'aläl "otra distinta, una muchacha». En ninguno de estos casos se asume una secuencia de narrativa mínima entre las acciones del niño en la primera imagen y en la segunda, pues ni siquiera se considera que los dos niños retratados se refieren al mismo niño.

Por último, el caso más curioso es el de una mujer que, no solamente no utilizó ninguna narrativa secuencial para referirse a la conexión entre las acciones del niño en la primera imagen y la segunda, sino que ni siquiera reparó en el niño. Mientras mira atentamente las plantas que aparecen en el plano secundario del dibujo y apunta hacia ellas con el dedo, dice:

(7) Sana'orya wol loñk'el aj ili.

Esto que estamos viendo aquí es zanahoria.

(8) Aj-ili chébä... krabano ix tyi ya'i.

Este de aquí es rábano.

En muchas culturas occidentales, como se ejemplifica en la descripción del hablante norteamericano al principio de esta sección, en una imagen en la que existen personas en primer plano, las personas suelen ser lo que en la psicología Gestalt se ha denominado "figura», y el paisaje forma parte del «fondo». Discriminar entre figura y fondo es un proceso complejo, donde el cerebro procesa distintos tipos de información a la vez, como el tamaño de los objetos, su color y posición, y donde indudablemente juegan también un papel las concepciones culturales acerca de jerarquías de importancia implicadas en las relaciones entre los objetos entre los que se está discriminando. Lo verdaderamente sorprendente en este caso no es ya la falta absoluta de implicatura de secuencialidad entre las cláusulas (7) y (8), sino la completa inversión de figura y fondo (Wagner, 1986), donde el niño se convierte en un elemento completamente secundario y sin importancia del fondo, y lo que verdaderamente pasa a ser "figura» en primer plano es el paisaje, en concreto, las plantas. 


\section{Un nuevo test de secuencialidad}

Los hablantes monolingües choles con los que reproduje el famoso estudio de Slobin (1987) no describían la historia Rana, ¿dónde estás? en términos secuenciales, y tampoco identificaban la secuencialidad implícita en la narrativa mínima del niño bañándose y después vistiéndose. Si al lector le pueden parecer inusuales las descripciones choles de la imagen de la Figura 3, puedo asegurarle que mayor era la sorpresa de esta antropóloga al obtener tales respuestas, como la persona que se frota, incrédula, los ojos ante algo que está viendo pero le cuesta creer, pensando que su visión le engaña. Este extrañamiento se debía a que resulta sumamente difícil desprenderse de las categorías propias cuando intentamos analizar y comprender las categorías de una cultura ajena. Esta dificultad ha sido reconocida hasta la saciedad en tratados de metodología antropológica. Como señala Agar, el etnógrafo «lucha internamente con la interferencia de su propia forma de pensar, sentir, y actuar» (Agar, 1996: 58).

Aún llena de escepticismo, pensé que, quizá, el curioso efecto que estaba observando se debía no a una cosmovisión radicalmente distinta, sino a que la implicatura en el caso de la imagen del niño bañándose y después vistiéndose podía ser poco clara, por lo que diseñé tres viñetas donde la secuencia de acciones implicada entre las imágenes se hacía cada vez más explícita. Lo que pretendía averiguar con este pequeño experimento era cómo de explícita tenía que ser la idea de secuencialidad para hacerse evidente a los ojos de un chol. En las tres viñetas se retrataba la historia de un niño que subía a coger fruta de un árbol y luego se caía del mismo. La primera viñeta solo constaba de dos imágenes secuenciales (Figura 4), la segunda constaba de tres (Figura 5) y la tercera viñeta contenía cinco imágenes secuenciales (Figura 6). Las tres viñetas se referían a la misma historia, pero cuantas más imágenes contenía la viñeta, más explícita era la secuencialidad implicada en las acciones del personaje. A cada hablante le enseñé las tres viñetas, empezando por el nivel menos explícito y finalizando por el más explícito.

El primer nivel (Figura 4) consta únicamente de dos imágenes: en la primera se muestra a un niño mirando una fruta que está en un árbol y en la siguiente imagen el niño aparece al otro lado del árbol, sentado en el suelo, y frotándose los glúteos: 


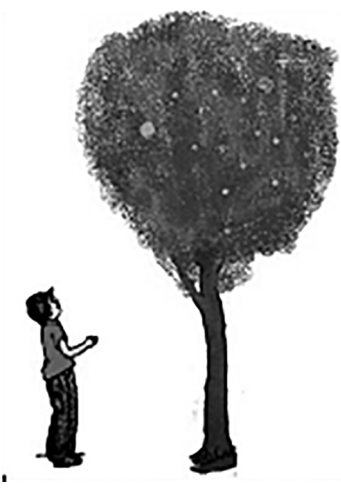

A

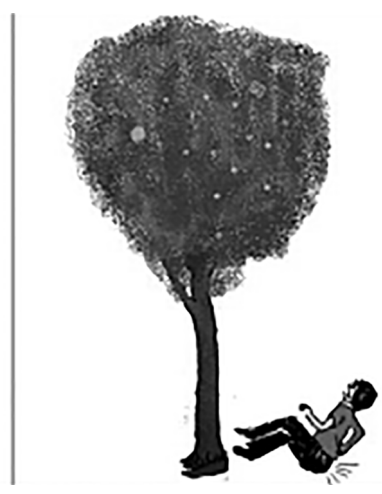

E

Figura 4. Test de secuencialidad: nivel 1. Viñeta dibujada por el antropólogo Sergio D. López. Las letras «A-E» no aparecen en la imagen que se utilizó en el estudio.

Los hablantes de lenguas indoeuropeas a quienes se les muestra esta imagen la suelen describir en estos términos: "hay un niño que está mirando al árbol, quiere coger una fruta, para cogerla se sube al árbol, y luego se cae». Incluso aunque ciertos «episodios» de la secuencia de acontecimientos no figuren de manera explícita en la imagen —en concreto el episodio donde el niño supuestamente sube al árbol-, la tendencia es a asumir de forma casi automática la relación causal entre la situación en la imagen A y la situación en la imagen E. Si un personaje está mirando a una fruta que está en lo alto de un árbol y en la siguiente viñeta se ha caído, lo «lógico» es que haya intentado trepar a por la fruta y se haya caído después. Pero este tipo de razonamiento no pareció ni lógico ni relevante a ninguno de los hablantes choles a quienes les mostré la Figura 4.

Al igual que con algunas de las descripciones de las imágenes del niño bañándose en el río y después vistiéndose, la primera cosa que mencionaron los cuatro hablantes choles a quienes les mostré la Figura 4 fueron los árboles, no el niño. Ni un solo hablante dio una descripción secuencial de las dos imágenes, pero todos mencionaron que había un niño que estaba mirando al árbol porque quería trepar por él. Esto es también una implicatura, pero es una implicatura puramente chol, no indoeuropea u occidental. Si para un hablante de español la implicatura es «primero ocurre A» (el niño quiere conseguir la fruta) y «luego ocurre E» (el niño se ha caído del árbol), la implicatura en chol no relaciona $\mathrm{A}$ y E. Es una «intra-implicatura», en el sentido de que amplía el contenido 
de lo que pasa en A, o de lo que pasa en E. Si observamos cuidadosamente, ambos niños parecen estar mirando la fruta del árbol, no solo el niño en la imagen A.

Para una de las hablantes choles, había dos hombres en la imagen. Esto es un efecto idéntico al de la imagen del niño bañándose en el río, que algunos choles interpretaron como dos niños haciendo acciones independientes. Esta hablante inicia su descripción indicando que hay un hombre cortando fruta: wutyi, ila choñkol ik'el letsel ili. Choñk tyi bok'el li wiñiki, "Está mirando para subir a por la fruta. El hombre la quiere cortar». De nuevo, esto es otra intra-implicatura de la imagen A, pues verdaderamente el hombre en la imagen solo está mirando la fruta. Pero ¿qué otro sentido, en la lógica cultural chol, puede tener que el hombre esté mirando la fruta? Inmediatamente después se da cuenta de que hay «otro» hombre, que está sentado. En vez de haberse caído, el hombre sentado también está mirando al árbol porque quiere trepar a él:

(9) Weñ chañ ili tye'i.

$\mathrm{El}$ árbol es muy alto.

(10) Li yañbä buchul choñkol ik'el letsel.

El otro sentado está mirando para subir.

Para otra hablante, en la imagen también había dos niños, que no están conectados el uno con el otro:

(11) Yila ibaj ili, choñkol ik'el yila ili la’bä añtyak.

Parece que este aquí, parece que está mirando lo que hay ahí [apunta a la imagen A].

(12) Choñk tyi ch'ämtyam je'el yila ili, la'ta' kawakña ityi' ik'el letsel. Este de aquí está mirando también, el de aquí con su boca abierta está mirando para trepar (al árbol) [apunta a la imagen E].

Después, esa misma hablante continúa diciendo que el árbol es hermoso, y describe sus flores y raíces. Finalmente, dirige de nuevo su atención al niño en la parte derecha de la imagen (E), describiendo con mayor detalle lo que ve allí, pero en ningún momento la conecta secuencialmente con la imagen A:

(13) La'ix poj buchul, weñ k'el ili, k'atyi ye'e ipaty. Aquí está sentado, mira mucho (hacia arriba), se está tocando su espalda con su mano. 
Las descripciones de la Figura 4 son muy parecidas a las de la Figura 3 , pues en ningún caso desvelan la secuencialidad implícita entre las imágenes A y E. Esto se demuestra claramente mediante el uso de pronombres y adjetivos demostrativos diferenciados para hablar de los dos niños: «este... el otro» o "este», señalando al niño en la imagen A y «este de aquí» señalando al niño en E. Lo que es notable en varios casos es el uso de la «intra-implicatura»: en lugar de prestar atención a la secuencialidad implicada entre las dos imágenes, los hablantes choles reparan en lo que cada una de las imágenes, por separado, implica: que una persona -esté de pie (imagen A) o «sentada» (imagen E)— esté mirando a un árbol puede implicar que quiera subirse a él, o que quiera cortar fruta, pero lo que definitivamente no implica, desde la perspectiva chol, es que los dos hombres son la misma persona en distintos momentos de una secuencia temporal.

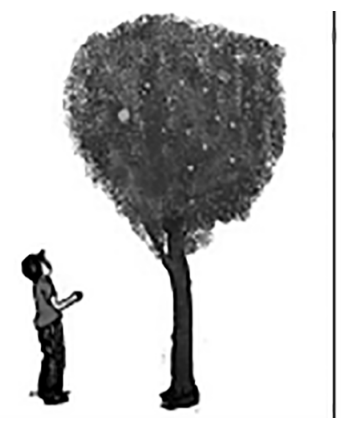

A

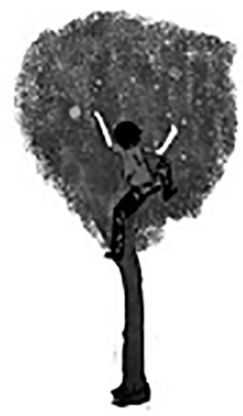

C

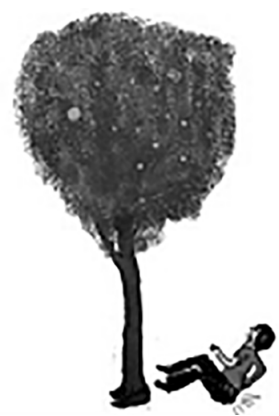

$\mathrm{E}$

Figura 5. Test de secuencialidad: nivel 2.

El segundo nivel consiste en una secuencia de tres imágenes, donde se añade la imagen C como eslabón entre A y E, y donde ahora la implicatura de secuencia temporal es mucho más clara que en la Figura 4. A pesar de esta nueva imagen añadida, ninguno de los hablantes produjo una descripción claramente secuencial donde A precede a C, y C precede a E. El uso repetido de pronombres personales tiene como efecto una ambigüedad con respecto a si hay un hombre o varios. No obstante, incluso dentro de esta ambigüedad resulta evidente que los hablantes no están ordenando mentalmente los episodios de la secuencia A-C-E.

La primera hablante a la que le mostré la figura únicamente dijo que había árboles, y un niño que estaba jugando y mirando a los árboles. Otra hablante comienza a describir la figura mientras su mirada recorre las imágenes de derecha a izquierda. No está claro si ella piensa que hay un 
niño haciendo varias acciones, o varios niños haciendo varias acciones, pero, en cualquier caso, dada su interpretación de la imagen E, resulta claro que no está ordenando mentalmente las imágenes en una secuencia cronológica, donde $\mathrm{A}$ es el evento anterior, $\mathrm{E}$ el posterior, y $\mathrm{C}$ es un evento intermedio:

(14) Ili choñk weñ k'el maje ila.

Este [niño en la Imagen E, a la derecha] está mirando mucho para subir ahí.

(15) Poj tyijikña yubi che' añ tyi iyébal yila.

Está contento, porque está debajo (del árbol).

(16) Tyijikña che’ li... poj buchuloñla tyi iye’ tye'el.

Se está contento cuando... nos sentamos debajo de un árbol.

(17) La'ix choñkol letsel ityuk ta' yila ibaj ili.

Aquí parece que él/este [niño en la Imagen C, en el centro] está subiendo a cortar (fruta).

(18) Ix choñkol letsel k'el iyalo' ambä wutyi.

Ahí está mirando [el niño en la Imagen A, a la izquierda] para subir donde están las frutitas.

Dado el uso de los pronombres idénticos «ili» «él/este» en (14) y (17) para referirse a los niños que están en la imagen, no es posible saber si la hablante se está refiriendo a un niño o varios. Este pasaje podría interpretarse como una descripción de actividades paralelas: un niño está bajo el árbol, el mismo niño u otro niño corta fruta, y el mismo niño u otro niño está mirando para subirse al árbol. Otra interpretación es que la hablante está describiendo a un niño haciendo varias actividades, y que existe una conexión secuencial entre esas tres actividades: estar sentado bajo el árbol, cortar fruta, y mirar al árbol para subirse. Pero si este fuera el caso, estamos de vuelta donde empezamos con las historias tradicionales choles: no es que no existan secuencias temporales en estas historias, sino que no es posible ordenarlas cronológicamente. La lógica indoeuropea y occidental dicta que el orden cronológico de las tres imágenes es mirar el árbol, subirse a él y caerse, donde trepar al árbol es anterior a caerse de él. En la "historia» de esta hablante chol, resulta evidente que, incluso en el caso de esta dudosa secuencia, no hay conexión entre C y E: el niño no "cae» porque antes ha trepado, sino que está «sentado» (buchul) porque es agradable sentarse a la sombra de los árboles, como se dice en la frase: 
(16) «Se está contento cuando nos sentamos debajo de un árbol».

La descripción más secuencial de la Figura 5 la da esta otra persona:

(19) Choñkol iletsel tyi tye' yila ili.

Parece que él/este se está subiendo al árbol [apunta con el dedo a la imagen $\mathrm{C}$, en el centro].

(20) Choñkol iñop tyi tyukbeñ iwuty.

Está intentando cortar su fruta.

(21) Ta'ix ujtyi tyuk kilañ.

Terminó de cortar todo [apunta con el dedo a la imagen E, a la derecha].

(22) La'ix choñkol ik'ele maje pamil ila.

Aquí está viendo dónde va a salir [apunta con el dedo a la imagen $\mathrm{A}$, a la izquierda].

De nuevo, incluso asumiendo la presencia de una dudosa secuencialidad en esta descripción, el orden de tal «secuencia» no lleva a la hablante a la conclusión de que el personaje en $\mathrm{E}$ se haya caído del árbol tras trepar por él, como se muestra en la imagen C. Para esta hablante, el personaje en la imagen E no se ha caído, sino que simplemente ha terminado de cortar la fruta. Además, el orden en el que describe la «secuencia» no es «A (mirar) - C (trepar) - E (caer)», sino «C (trepar) - E (terminar) - A (mirar)».

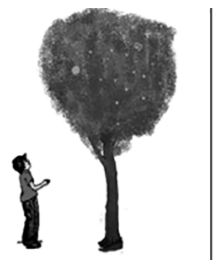

A

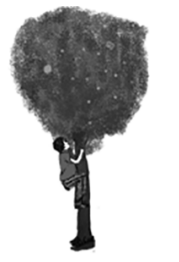

B

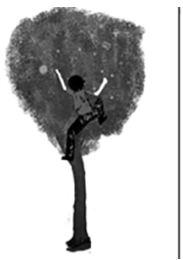

C

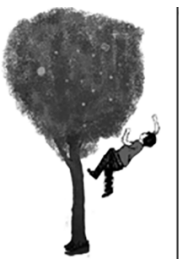

$\mathrm{D}$

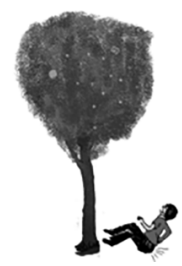

E

Figura 6. Test de secuencialidad: nivel 3.

Como se puede apreciar en la Figura 6, en esta viñeta la implicatura de secuencialidad debería ser bastante clara. Pero las descripciones obtenidas no distan de las anteriormente proporcionadas. Una de las hablantes menciona a niños que están «en una línea» (ts'äyäkña) cortando fruta, 
pero no menciona al niño de la imagen E. Otra hablante, apuntando al niño de la imagen E, dice que «le duele la espalda». Esta es la primera descripción donde los choles interpretan que el niño de la imagen E siente incomodidad o dolor. Pero el vínculo secuencial entre ese dolor y la imagen anterior está, de nuevo, ausente en la descripción de la hablante. Para cerciorarme, le pregunté a la hablante la razón por la cual le dolía al niño la espalda: si hubiera algún tipo de secuencialidad implicada entre D y E, la hablante habría respondido algo parecido a "porque se cayó del árbol». En su lugar, esta es la respuesta que obtuve:

(23) Antropóloga.-Chukoch k'ux ipaty? ¿Por qué le duele la espalda?

(24) Doña Yolanda._- Machäch lakñatya(ñ), ichämeläch je'e(l) wa'le. No lo sabemos, debe ser su enfermedad también.

Resulta evidente que no existe para Doña Yolanda ningún tipo de conexión secuencial entre las imágenes D y E. Tan solo una de las tres hablantes a quienes mostré la Figura 6 dio una descripción que, en principio, parece incluir una narrativa mínima en la transición entre D y E. La descripción resulta un tanto ambigua pues para esta hablante no hay un único niño, sino varios. No obstante, en principio sí parece existir una conexión entre las imágenes D y E:

(25) Choñkol weñ letselob tyi tye' iliyi.

Muchos están subiendo al árbol aquí.

(26) Cha' mi ikäñob letsel tyi tye' ila.

Otra vez empiezan a subir al árbol.

(27) La'ix choñoxbä tyi yajlel.

Aquí [está] el que está cayendo.

(28) Táix xujli li ibaj!

¡Se fracturó!

Parece haber una conexión evidente entre «aquí está el que está cayendo" y «se fracturó». No obstante, puesto que no hay un sujeto explícito en ninguna de las dos oraciones, no podemos estar seguros de que se refiera a la misma persona, y que la hablante no esté describiendo acciones paralelas. Lo que la gramática chol marca de manera muy clara es el contraste entre la acción en $\mathrm{D}$, el niño "cayendo", que se expresa con 
aspecto progresivo en el verbo, y la acción en E, el niño que "se fracturó», que se expresa con aspecto perfectivo. Recordemos que en esta lengua los verbos se conjugan obligatoriamente con categorías aspectuales; el aspecto progresivo sirve para describir acciones que están en curso en la ocasión descrita por el hablante, y el aspecto perfectivo describe eventos $\mathrm{u}$ acciones que ya han sido finalizadas. Las palabras escogidas por la hablante muestran una precisión exquisita para describir la dinámica interna de cada imagen, pero no está claro, según lo que nos muestra la gramática chol, si verdaderamente la hablante asume una secuencialidad entre las oraciones (27) y (28). Para averiguar si efectivamente ambas oraciones comparten el mismo sujeto, y si las acciones en (27) y (28) son dos acciones secuenciales ejecutadas por el mismo niño o dos acciones paralelas ejecutadas por dos niños, de nuevo pregunté:

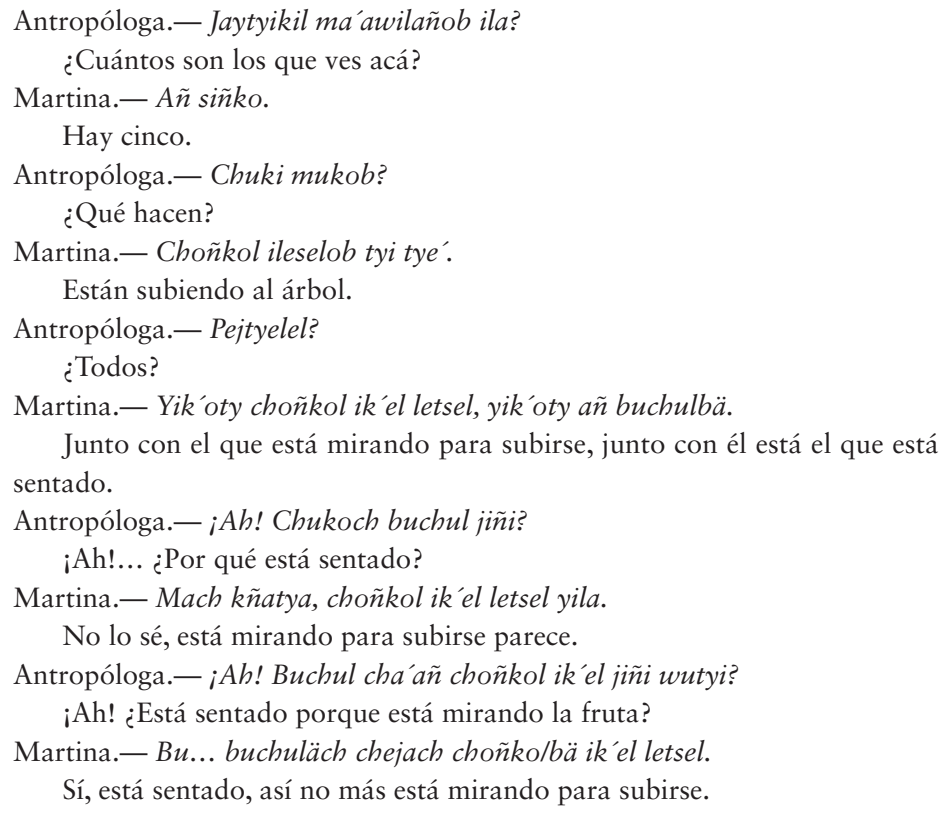

En esta ocasión, la hablante vuelve a describir al niño de la imagen $\mathrm{E}$ como ha sido descrito en múltiples ocasiones anteriores: buchuläch «sentado", porque quiere subir a por la fruta, no porque se haya caído. Por lo tanto, y especialmente siendo como es ambigua la gramática chol en cuanto al sujeto de las oraciones (27) y (28), no podemos estar completamente seguros de que a ojos de esta persona exista una conexión secuencial entre el niño que «está cayendo» y el que «se fracturó». 


\section{Conclusión. Efecto whorfiano y extrañamiento antropológico}

Habla Gerardo Fernández Juárez de «la capacidad de retorno de ese 'extrañamiento' que la visión del otro consigue devolvernos incluso en los escenarios más habituales» (2018: 350). Las lecciones que he aprendido y cada día continúo aprendiendo en mi exploración de la lengua y la cultura chol han resultado en un extrañamiento, pero no ante la lengua, la cultura, y el pensamiento chol, sino ante los propios, como describe Fernández Juárez. Volviendo sobre las imágenes tiempo después me di cuenta de hasta qué punto las descripciones de los choles eran tremendamente precisas, pues en las Figuras 3 y 4 no hay en realidad un niño, sino dos. Las descripciones choles, al contrario de lo que pueda parecer, no tienen nada de exótico. Lo verdaderamente «exótico» es lo que nosotros hacemos, añadiendo algo a la imagen, imaginando una historia que en realidad no existe. La idea de secuencialidad no es más que un filtro a través del que miramos esas imágenes que nos hace pasar a segundo plano $-\mathrm{y}$ a veces ni siquiera darnos cuenta de que existen - infinitos detalles sobre el paisaje, sobre los distintos tipos de plantas, sobre las rocas. Todos esos detalles sí están presentes en las descripciones choles, al contrario que el supuesto orden en que se desarrollan los acontecimientos, que hemos aprendido a asumir, pero que verdaderamente no está ahí. Nuestra presunción de secuencialidad no es más que una «experiencia ficticia del tiempo» (Ricœur, 1984). Contemplando una viñeta como la de la Figura 6 , lo que hacemos es transformar mentalmente el espacio - que es lo que describen los hablantes choles con gran precisión- en la secuencialidad, en el imaginado orden de los acontecimientos, y, en última instancia, en la propia noción de tiempo. Pero el verdadero efecto whorfiano, como algunos llaman a la relación entre la lengua, cosmovisión y pensamiento, no es que los choles no procesen la secuencialidad de imágenes porque su lengua no tenga tiempos verbales. Sencillamente, para los choles a los que mostré las imágenes, la noción de secuencialidad no es un elemento relevante. La sorpresa es que nosotros lo hacemos porque nuestras categorías gramaticales nos invitan a ello. Cuando hemos de marcar cada verbo con una inflexión que describe si el evento ocurre antes, durante, o después del momento del habla, comenzamos a sentir, a pensar, a percibir una inevitable secuencialidad que va más allá de las palabras, "viéndola» incluso donde en realidad no está.

Las respuestas que obtuve de mis amigos choles recuerdan a los famosos pirahã de la Amazonia brasileña, que prefieren restringir su comunicación a todo aquello que forma parte de su experiencia presente (Everett, 2005), o a los mayas mopán de Belize, para quienes no existe el 
género literario de ficción, e interpretan historias de ficción en películas o libros como historias que han ocurrido en la realidad (Danziger, 2010). También recuerdan a las que Alexander Luria, en los años treinta, obtuvo de campesinos rusos cuando les presentaba sus famosos silogismos, para investigar si estos eran capaces de realizar inferencias silogísticas. Dice Abdurakhm, un campesino ruso de 37 años de edad, en respuesta al silogismo de Luria:

Luria.- En el lejano norte, donde hay nieve, todos los osos son blancos. Novaya Zemlya [un pueblo] está en el lejano norte. ¿De qué color son los osos allí?

Abdurakhm.- Hay muchos tipos distintos de osos.

Luria.- Pero en el lejano norte, donde hay nieve, todos los osos son blancos. Novaya Zemlya [un pueblo] está en el lejano norte. ¿De qué color son los osos allí?

Abdurakhm.— No lo sé. He visto un oso negro, nunca he visto otros tipos... Cada localidad tiene sus propios animales: si los hay blancos, son blancos; si los hay amarillos, serán amarillos.

Luria.- Pero, ¿qué tipo de osos hay en Novaya Zemlya?

Abdurakhm. - Hablamos solo de lo que vemos. No hablamos de lo que no vemos

(Luria, 1976: 108-109, traducción propia).

La torpeza del joven Luria presionando a Abdurakhm, esperando obtener la respuesta de que «los osos son blancos» me hace sonreír, pensando en mi propia torpeza al preguntar a los choles una y otra vez «¿cuántos niños hay en la imagen?, ¿pero, por qué está el niño en el suelo?», cuando en realidad ni los osos eran blancos —iquién sabe de qué color son los osos en Novaya Zemlya! - ni solo había un niño. Y me hace apreciar la tremenda empatía y paciencia con la que respondían los choles, maravillándose quizá ante la incompetencia de esta antropóloga que, después de tanto estudiar, no sabía ni contar los niños que había en la imagen. Al igual que los campesinos rusos con los que trabajó Luria, los choles son más empiristas de lo que lo somos en culturas occidentales. Los choles no «inventan» aquello que no saben con certeza, no «asumen» historias que verdaderamente no existen, pero describen con exquisito detalle lo que ven. La disección, categorización y ordenación de la experiencia en un orden secuencial no es un requisito de su lengua, ni de su cultura. 
Cabe preguntarse si la lengua es el único factor que influye en esta peculiar interpretación de la idea de secuencialidad. Por supuesto que no lo es. A pesar de la profunda conexión que existe entre lengua, cosmovisión e identidad cultural, existen numerosas culturas que han perdido su lengua durante la colonización, y que, a pesar de ello, mantienen una identidad cultural distintiva. La lengua es un elemento clave para articular la cosmovisión, y provee a sus hablantes con categorías para codificar esa percepción de la realidad, pero no es el único elemento que influye en la cosmovisión y en la noción de secuencialidad. Muchos otros factores, y entre ellos de manera prominente la escolarización y el aprendizaje de la lectoescritura, ejercen una profunda influencia en la percepción de secuencialidad y en la propia noción del tiempo (Rodríguez, 2013; Tversky, Kugelmass y Winter, 1991).

Volvamos, a modo de conclusión, a una de las preguntas con las que inicié este artículo: ¿Puede un antropólogo estudiando una cultura ajena penetrar en un sustrato de la realidad más profundo de esa cultura si aprende la lengua? Mi respuesta, como a estas alturas probablemente pueda adivinar el lector, es sí. En palabras de Roman Jakobson: «La verdadera diferencia entre lenguas distintas no es lo que puede o no puede ser expresado, sino lo que debe o no debe ser expresado por sus hablantes» (1959: 142). Es un principio básico de la antropología lingüística que cualquier lengua es capaz de expresar cualquier concepto, siempre y cuando este responda a una necesidad presente en la cultura (Lippi-Green, 1997). Por lo tanto, la lengua no es un impedimento que nos fuerza a ver el mundo de determinadas maneras, creando barreras insuperables entre hablantes de lenguas distintas, como los babelistas suelen señalar. Lo que matizan Humboldt (1988), Jakobson (1959), Whorf (1956), Slobin (1987 y 1996) y tantos otros partidarios de la relatividad lingüística, es que, en el proceso de diseccionar y categorizar la realidad, y expresar esa realidad en palabras, dependemos en gran medida de los recursos discursivos disponibles en nuestras lenguas nativas, y lo que pensamos lo pensamos en clave de esas categorías gramaticales disponibles. Aprender esos recursos, esas categorías gramaticales, puede ser la clave de esa forma de pensar y categorizar la realidad que llamamos «cosmovisión», y, en última instancia, "cultura».

\section{Referencias}

Agar, M. (1996). The Professional Stranger. San Diego: Academic Press.

Alejos García, J. (1999). Ch'ol / Kaxlán : Identidades Étnicas Y Conflicto Agrario En El Norte De Chiapas, 1914-1940. México: Instituto de Investigaciones Filológicas, Centro de Estudios Mayas, Universidad Nacional Autónoma de México. 
Danziger, E. (2010). On Trying and Lying: Cultural Configurations of the Gricean Maxim of Quality. Intercultural Pragmatics, 7(2): 199-219.

Everett, D.L. (2005). Cultural Constraints on Grammar and Cognition in Pirahã. Current Anthropology, 46(4): 621-646.

Fernández Juárez, G. (2018). Un kallawaya en la «Gran Vía»: notas de campo en Madrid. AIBR: Revista de Antropología Iberoamericana, 13(3): 333-354.

Gentner, D. y Goldin-Meadow, S. (Eds.) (2003). Language in mind: Advances in the study of language and thought. Cambridge, MA: MIT Press.

Grice, P.H. (1975). Logic and conversation. En Syntax and Semantics 3: Speech Acts. P. Cole y J.L. Morgan, Eds.

Gumperz, J.J. y Levinson, S.C. (1996). Rethinking Linguistic Relativity. Cambridge: Cambridge University Press.

Humboldt, W.von (1988) [1836]. On language: the diversity of human language structure and ints influence on the mental development of mankind. Traducción de P. Heath. Cambridge University Press.

Imberton-Deneke, G.M. (2016). La voluntad de morir. El suicidio entre los Choles. México: Flacso México.

Imberton-Deneke, G.M. (2002). La vergüenza. Enfermedad y conflicto en una comunidad chol. Programa de Investigaciones Multidisciplinarias sobre Mesoamérica y el Sureste. México: Universidad Nacional Autónoma de México.

Jakobson, R. (1959). Boas' view of grammatical meaning. American Anthropologist, 61: 139-145.

Klein, W. (2009). How Time Is Encoded. En The Expression of Time. W. Klein y P. Li, Eds. Berlin: Mouton de Gruyter.

Labov, W. (1972). The Transformation of Experience in Narrative Syntax. En Language in the Inner City: Studies in the Black English Vernacular. W. Labov. Philadelphia: University of Pennsylvania Press.

Lee, P. (1996). The Whorf theory complex: A critical reconstruction. Amsterdam: John Benjamins.

Lippi-Green, R. (1997). English with an Accent: Language, Ideology, and Discrimination in the United States. New York: Routledge.

López Martínez, S.D. (2013). Santos familiares y brujos. Análisis de creencias y disputas sociales en dos relatos choles. Entre Diversidades, 1(1): 149-170. En https://doi. org/10.31644/ED.1.2013.a05.

Lucy, J. (1997). Linguistic relativity. Annual Review of Anthropology, 26: 291-312.

Lucy, J. (1992a). Language Diversity and Thought: A Reformulation of the Linguistic Relativity Hypothesis. Cambridge: Cambridge University Press.

Lucy, J. (1992b). Grammatical Categories and Cognition: A Case Study of the Linguistic Relativity Hypothesis. Cambridge: Cambridge University Press.

Luria, A.R. (1976). Cognitive Development. Its Cultural and Social Foundations. Cambridge, MA: Harvard University Press.

Mayer, M. (1969). Frog, Where Are You? New York: Dial Press. 
McWhorter, J.H. (2014). The Language Hoax: Why the World Looks the Same in Any Language. New York: Oxford University Press.

Pérez Chacón, J.L. (1988). Los Choles De Tila Y Su Mundo. Tradición Oral. Edición bilingüe: Chol - Español. Traducido por M. Pérez López y A. Pérez López. Tuxtla Gutiérrez: Gobierno del Estado de Chiapas. Instituto Chiapaneco de Cultura.

Pinker, S. (2007). The Stuff of Thought: Language as a Window into Human Nature. New York: Viking.

Ricœur, P. (1984). Time and narrative. Chicago: University of Chicago Press.

Rodríguez, L. (2019). Time is not a line. Journal of Pragmatics, 151: 1-17.

Rodríguez, L. (2016). From Discourse to Thought: An Ethnopoetic Analysis of a Chol Mayan Folktale. Signs and Society, 4(2): 278-301.

Rodríguez, L. (2013). Bilingualism and literacy-driven change in co-speech gesture. Panel: Multilingualism and multimodality in interaction. $112^{\text {th }}$ Annual Meeting of the American Anthropological Association, Chicago.

Secretaría de Educación Pública (1981). Mi Primer Libro. México: Dirección General de Publicaciones y Bibliotecas de la Secretaría de Educación Pública.

Slobin, D.I. (1996). From «thought and language» to «thinking for speaking». En Rethinking Linguistic Relativity. J.J. Gumperz y S.C. Levinson. Cambridge University Press.

Slobin, D.I. (1987). Thinking for Speaking. Proceedings of the Annual Meeting of the Berkeley Linguistics Society: 435-445. Berkeley, CA: University of California Press.

Tanu, D. y Dales, L. (2016). Language in fieldwork: Making visible the ethnographic impact of the researcher's linguistic fluency. The Australian Journal of Anthropology, 27: 353-369.

Tonhauser, J. (2015). Cross-linguistic Temporal Reference. Annual Review of Linguistics, 1: 129-54.

Tversky, B.; Kugelmass, S. y Winter, A. (1991). Cross-Cultural and Developmental Trends in Graphic Productions. Cognitive Psychology, 23: 515-57.

Vázquez Álvarez, J.J. (2011). A Grammar of Chol, a Mayan Language. Tesis Doctoral. University of Texas, Austin.

Villeneuve, D. (Director) (2016). Arrival. Estados Unidos: Film Nation Entertainment, Lava Bear Films, 21 Laps Entertainment. D. Levine, S. Levy, D. Linde y A. Ryder, Productores. Wagner, R. (1986). Symbols that Stand for Themselves. Chicago: Chicago University Press. Whorf, B.L. (1941). The Relation of Habitual Thought and Behavior to Language. En Language, Culture, and Personality, Essays in Memory of Edward Sapir. L. Spier, Ed. Menasha: Sapir Memorial Publication Fund.

Whorf, B.L. J. (1956). Language, Thought, and Reality: Selected Writings. J. B. Carroll, Ed. Cambridge, MA: Technology Press Books in the Social Sciences. 
